\title{
Urgency for surgical evacuation of post traumatic Intracranial acute epidural hematoma
}

\author{
Mishra GP' ${ }^{1}$, Najm us Saqib², Azmat Ali ${ }^{3}$, Mohammad Hashim Awad ${ }^{4}$, Syed Osama Mehboob ${ }^{5}$ \\ ${ }^{1}$ Dr GP Mishra Senior consultant \& Head department Neurosurgery, ${ }^{2}$ Dr Najm us Saqib Specialist Neurosurgeon \\ Department Neurosurgery, ${ }^{3}$ Dr Azmat Ali Specialist Neurosurgeon department Neurosurgery, ${ }^{4}$ Dr Mohammad Hashim \\ Awad Resident, Department Neurosurgery. All are affiliated with Khoula hospital, Ministry of health, Muscat. Oman. \\ ${ }^{5}$ Syed Osama Mehboob, Clinical research fellow, Ninewells hospital. Dundee. United Kingdom
}

Address for Correspondence: Dr Najm us Saqib, Email: drnajam@mail.ru

\begin{abstract}
Introduction: Intracranial epidural haematoma, $(\mathrm{EDH})$ is a collection of blood between the skull and dura mater due to head injury. It is considered to be the most serious complication of head injury requiring immediate diagnosis and surgical intervention. Background: The aim of our study was to present the outcome of consecutive patients with Acute EDH managed surgically \& to prove the high risk of death or permanent brain damage without prompt surgical intervention. Method: In this study we retrospectively examined all consecutive head injury cases managed between September 2014 \& September 2015 and diagnosed with acute traumatic epidural hematoma in isolation or in combination with intra cranial lesions. Age, sex, mechanism of injury, time of presentation, Glasgow Coma Score (GCS), pupil reactivity, time of surgery and clinical outcomes were evaluated. Results: Out of 31 cases $87 \%$, (n=27) were males and $13 \%,(n=4)$ were females. The mean age was 17.75 years. $74 \%(n=23)$ patients under the age of $25 y$ years. The most common mode of injury was road traffic accident $48 \%,(n=15)$ followed by fall $42 \%,(n=13)$. The mortality rate was $6 \%$ $(n=2)$. The time interval between trauma \& operation of both patients who died were more than 8 hours. Conclusions: An acute epidural hematoma is an emergency condition, the diagnosis of the EDH must be promptly made by CT scan and the patient should be immediately transferred into a neurosurgical centre, Early surgical intervention is associated with the best outcome.
\end{abstract}

Keywords: Intracranial Epidural Haematoma, Brain Damage, Craniotomy, Dura Mater, Middle Meningeal Artery, Mechanism of Injury.

\section{Introduction}

Intracranial epidural haematoma, $(\mathrm{EDH})$ is a collection of blood between the skull and dura mater due to head injury. EDH mostly results from injury of the middle meningeal artery. Also, injury of the middle meningeal vein, diploic veins, or dural venous sinuses may lead epidural hemorrhage [1]. The incidence of EDH among traumatic brain injury (TBI) patients has been reported to be in the range of 2.7 to $4 \%$ [2]. Mortality rate associated with EDH are $20 \%$ [3]. The early mortality rate was $86 \%$ [4], which has reduced now by introduction of CT and proper resuscitative measures and timely surgical intervention. EDHs are nearly always caused by, and located near a skull fracture. The

Manuscript received: $11^{\text {th }}$ Oct 2015

Reviewed: $20^{\text {th }}$ Oct 2015

Author Corrected: $10^{\text {th }}$ Nov 2015

Accepted for Publication: $15^{\text {th }}$ Nov 2015 collection takes several forms in terms of size, location, speed of development and the effect they exert on patients. EDH usually forms within a matter of hours

from the time of injury but sometimes run a more chronic course, being detected only days after injury [6].

A lot of factors acting independently affect outcome in patients with acute traumatic EDH. Admission Glasgow Coma Score (GCS) and the presence of associated intracranial lesions appear to be the most important predictors of outcome. Other risk factors that may affect the eventual outcome of EDH are age of the patient, temporal or posterior fossa location, time interval between injury to surgical procedure, immediate coma 
or lucid interval, pupillary abnormalities, focal deficits on admission, CT findings (hematoma volume, degree of midline shift, signs of active bleeding). Patients who have higher EDH volumes usually have a worse prognosis. [7].

The standard recommendation for symptomatic patients is surgical intervention within the golden hours [5]. The preferred surgical intervention for EDH is craniotomy and evacuation of hematoma. However, neurosurgical service in Oman is still evolving and as such, there tends to be an unacceptable delay before an appropriate referral of patients to a competent neurosurgical centre. In developing countries with inadequate manpower and lack of essential diagnostic imaging support services, factors like late recognition and delay in seeking proper expert intervention may also indirectly affect the outcome in these patients.

The aim of our study was to determine the independent influencing factors, Present the outcome of consecutive patients with acute EDH managed surgically \& to prove the high risk of death or permanent brain damage without prompt surgical intervention.

\section{Methods}

\section{Results}

There were 31 acute EDH patients from September 2014 and September 2015, surgically managed at the department of neurosurgery, Khoula hospital, Ministry of health Muscat Oman. Out of 31 cases 87\%, (n=27) were males and $13 \%$,( $\mathrm{n}=4)$ were females. The mean age was 17.75 years. $94 \%(n=29)$ patients under the age of 35years. We found the most common mode of injury was road traffic accident $48 \%$, $(n=15)$ followed by fall $42 \%$, $(n=13)$. Most common clinical presentation was headache/vomiting $58 \%,(n=18)$ followed by altered sensorium $(n=7) .8$ patients were deeply unconscious at the time of admission, while 8 patients $(26 \%)$ had pupillary abnormalities.

According to CT finding, temporoparietal site was involved in $42 \%(n=13)$ followed by frontal region in $29 \%$ ( $n=9)$. Two patients $(6 \%)$ had EDH in posterior fossa. Associated extra cranial injuries (Long bone fracture, maxillofacial injury, Lung contusions) were present in $29 \%(\mathrm{n}=9)$ cases.

Out of 31 patients $65 \%,(n=20)$ were referred from peripheral centre (most of them are situated 2-4hours drive from Khoula hospital ), As Khoula hospital is a tertiary care referral hospital. All the cases were operated on emergency basis. Surgical management consisted of craniotomy under general anesthesia and removal of the hematoma. The mean time of interval between trauma \& operation was 6.38 hours. In terms of the Glasgow Coma Scale, 87\%, $(n=27)$ patients presented complete recovery, while two patients $6 \%$ had severe neurological sequelae. The mortality rate was $6 \%(\mathrm{n}=2)$.

The time interval between trauma $\&$ operation of both patients who died more than 8 hours \& they transferred from Peripheral centre. 
Table I: Demographic and clinical data of acute traumatic EDH.

\begin{tabular}{|c|c|c|}
\hline Features & Number (n) & Percentage \\
\hline No. of patients & 31 & \\
\hline \multicolumn{3}{|l|}{ Sex } \\
\hline Male & 27 & 87 \\
\hline Female & 04 & 13 \\
\hline \multicolumn{3}{|l|}{ Age (mean age 17.75) } \\
\hline 0 to 2 years & 02 & 6 \\
\hline 3 to 16 years & 10 & 32 \\
\hline 17 to 35 years & 17 & 55 \\
\hline 36 to 60 years & 02 & 6 \\
\hline 61 and more & 0 & 0 \\
\hline \multicolumn{3}{|l|}{ Mode of injury } \\
\hline Fall from height & 13 & 42 \\
\hline RTA & 15 & 48 \\
\hline Assault & 01 & 3 \\
\hline Fall of heavy object on head & 02 & 6 \\
\hline \multicolumn{3}{|l|}{ Site of EDH } \\
\hline Teporoparital & 13 & 42 \\
\hline Frontal & 09 & 29 \\
\hline parital & 03 & 10 \\
\hline Temporal & 02 & 6 \\
\hline Occipital & 02 & 6 \\
\hline Posterior fossa & 02 & 6 \\
\hline \multicolumn{3}{|l|}{ On arrival GCS } \\
\hline 13 to 15 & 19 & 61 \\
\hline 10 to12 & 04 & 13 \\
\hline 7 to 9 & 06 & 19 \\
\hline 3 to 6 & 02 & 6 \\
\hline \multicolumn{3}{|c|}{$\begin{array}{l}\text { Time interval between trauma } \\
\text { \& Operation }\end{array}$} \\
\hline $0-4$ hours & 12 & 39 \\
\hline $5-8$ hours & 14 & 45 \\
\hline 9 hours and more. & 05 & 16 \\
\hline Deaths & 2 & 6 \\
\hline
\end{tabular}

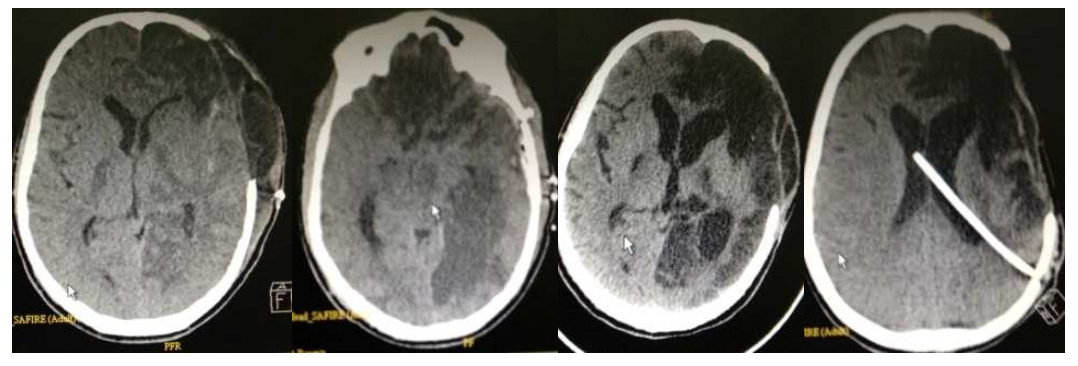




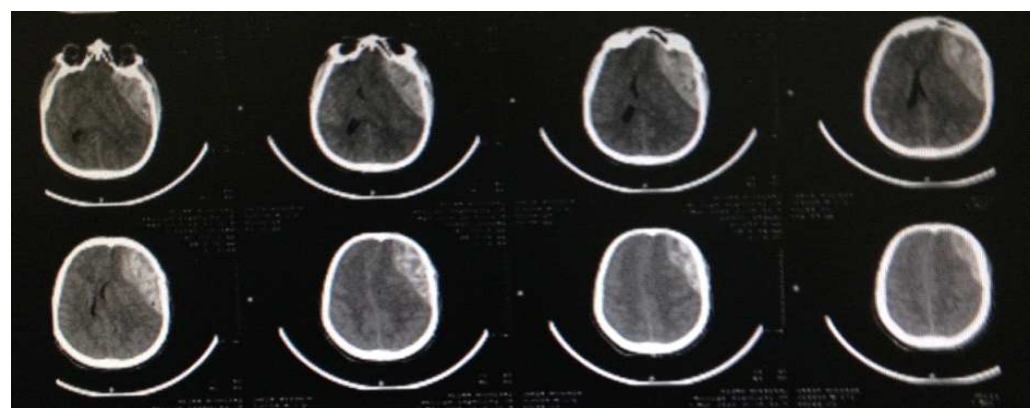

Figure 1 \& 2: 27 years old patient, transferred from peripheral hospital with the diagnosis of traumatic acute EDH, operated after 9 hours of head injury, Post op scan showed ipsilateral brain infarction, Further decompressive craniectomy obtained, late developed hydrocphalus. VP shunt inserted. Patient remains in vegetative status.

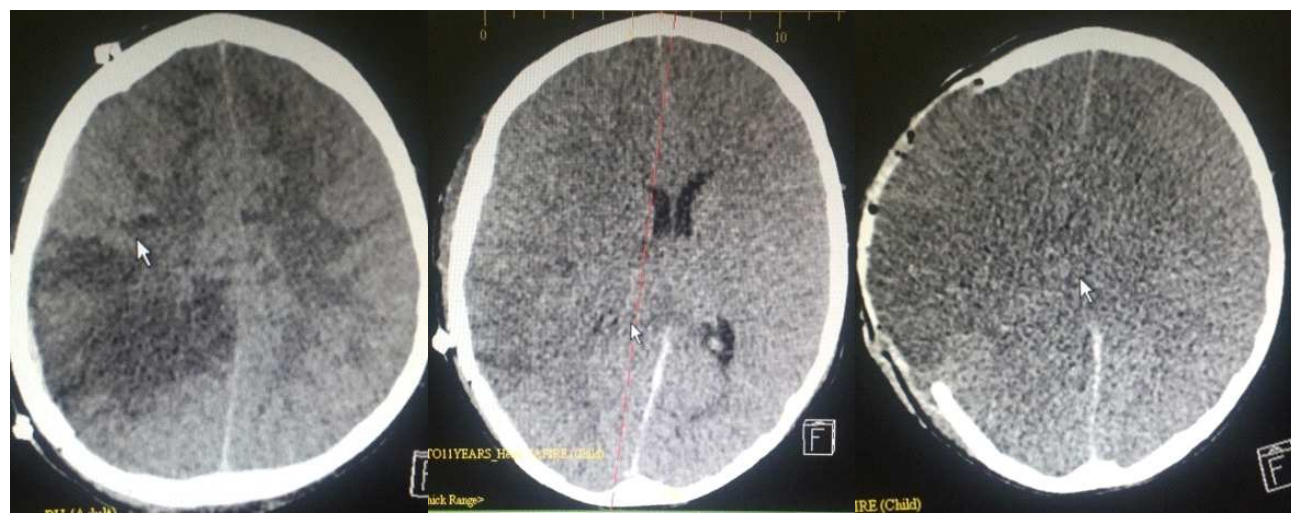

Figure 3: 9 years old boy. Operated for acute EDH after 11 hours of head injury. extensive brain infarcts deep the site of operated EDH. patient died.

\section{Discussion}

The classical clinical presentation of EDH includes a brief posttraumatic loss of consciousness, followed by a "lucid interval" of variable duration and then headache, depressed conscious state, contralateral hemiparesis and ipsilateral pupillary dilatation. Deterioration usually occurs due to a cerebral herniation. Clinical findings are highly variable, often unreliable for EDH and can delay the diagnosis, the diagnostic method of choice being the CT scan [8].

This study include only surgically managed cases of traumatic acute EDH. The acute epidural hematoma considered as a neurosurgical emergency and an urgent evacuation was recommended, The delayed diagnosis and treatment of EDH are related to increased mortality and worse functional outcome [7]. The aim of our study was to present the outcome of consecutive patients with Acute EDH managed surgically \& to prove the high risk of death or permanent brain damage without prompt surgical intervention.
Road traffic accident are the predominant predisposing factors in our study, accounting for $48 \%$ of patients. This reflects the serious impact of road traffic accident in our society. Since this factor is eminently preventable by proper enforcement of driving regulations, coordinated efforts may significantly reduce the rate of head trauma generally. Studies in pediatric populations indicate a high incidence of falls [9] and this is also modifiable.

Admission GCS is one of the most important predictors of eventual patient prognosis, outcome being better when the initial GCS is high [10]. In our study 20 patients shows best outcome with GCS $\geq 10$.

There is an established relationship between outcome of patients and the time lag between injury and surgical intervention. Surgical decompression should be carried out within $240 \mathrm{~min}(4 \mathrm{~h})$ of the onset of significant symptoms in order to ensure good result [11]. Our study strongly supported for these recommendations. Five patients with GCS between 7 to 9, Operated within 2-4 hours of injury \& showed good outcome. One patient who was transferred from peripheral hospital, 
developed severe neurological deficit, He was operated after 9 hours of head injury, Post op scan showed ipsilateral brain infarction, a further decompressive craniectomy was performed, This patient later developed hydrocphalus and a VP shunt had tobe inserted, He remains in vegetative status.

The overall mortality rate from this study was $(6 \%)$ as compare to some other studies, Chowdhury et al reported $8 \%$ mortality, While Bricolo et al reported $14 \%$ mortality $[6,10]$. These findings could largely be explained by delayed presentation to neurosurgical centre. In our study the time interval between trauma \&

\section{References}

1. Araujo JL, Aguiar Udo P, Todeschini AB, Saade N, Veiga JC. Epidemiological analysis of 210 cases of surgically treated traumatic extradural hematoma. Rev Col Bras Cir. 2012 Jul-Aug;39(4):268-71.

2. Bullock MR, Chesnut R, Ghajar J et al. Surgical Management of acute epidural haematomas. Neurosurgery. $2006 \quad$ Mar;58(3 Suppl):S16-24; discussion Si-iv.

3. Cheung PS, Lam JM, Yeung JH, Graham CA, Rainer TH. Outcome of traumatic extradural haematoma in Hong Kong. Injury. 2007 Jan;38(1):76-80. Epub 2006 Nov 13.

4. Jacobson HA. On middle meningeal haemorrhage. Guys Hos Rep 1964; 43:143 - 308. 20

5.Royal College of Surgeons of England Trauma Comm ittee.The Royal College of Surgeons of England:a positi on paper on the acute management of patients with head injury (2005). Ann R Coll Surg Engl. 2005 Sep;87(5):323-5.

6. Chowdhury Noman Khaled et al.: Surgical management of traumatic extradural haematoma: Experiences with 610 patients and prospective analysis. operation of both patients who died more than 8 hours $\&$ they also transferred from Peripheral centre.

\section{Conclusion}

We conclude that the acute epidural hematoma is an emergency condition, appears more often in males, The diagnosis of the EDH must be promptly made by CT scan and the patient should be immediately transferred into a neurosurgical centre, Early surgical intervention is associated with the best outcome.

\section{Funding: Nil,Conflict of interest: None. Permission of IRB: Yes}

Indian Journal of Neurotrauma (IJNT) 2008, Vol. 5, No. 2, pp. 75-79

7. Pereira CU, Santos EAS, Cavalcante S, Serra MV, Pascotto D, Fontora EAF. Hematoma extradural intracraniano. J bras neurocir. 2005;16(1):25-34.

8. Ligia Tataranu, Vasile Ciubotaru, Dan Paunescu, Andrei Spatariu, Mugurel Rado. Extradural hematoma is surgery always mandatory? Rom J Leg Med [22] 45 50 [2014].DOI: $10.4323 /$ rjlm.2014.45

9. Gerlach R, Dittrich S, Schneider W, Ackermann H, Seifert V, Kieslich M. Traumatic epidural hematomas in children and adolescents: outcome analysis in 39 consecutive unselected cases. Pediatr Emerg Care. 2009 Mar;25(3):164-9. doi: 10.1097/PEC.0b013e31819a8966.

10. Bricolo AP, Pasut LM. Extradural hematoma: toward zero mortality. A prospective study. Neurosurgery. 1984 Jan;14(1):8-12.

11.

Royal College of Surgeons of England Trauma Commit tee. The Royal College of Surgeons of England: a position paper on the acute management of patients with head injury (2005). Ann R Coll Surg Engl. 2005 Sep;87(5):323-5.

\section{How to cite this article?}

Mishra GP, Najm us Saqib, Azmat Ali, Mohammad Hashim Awad, Syed Osama Mehboob. Urgency for surgical evacuation of post traumatic Intracranial acute epidural hematoma. Int J Med Res Rev 2015;3(10):1146-1150. doi: 10.17511/ijmrr.2015.i10.207. 